\title{
Adaptive strategies of African horse sickness virus to facilitate vector transmission
}

\author{
Anthony Wilson, Philip Scott Mellor*, Camille Szmaragd, \\ Peter Paul Clement MerTens
}

\begin{abstract}
Vector-Borne Disease Programme, Institute for Animal Health, Ash Road, Pirbright, Woking, Surrey, GU24 0NF, United Kingdom
\end{abstract}

(Received 9 September 2008; accepted 16 December 2008)

\begin{abstract}
African horse sickness virus (AHSV) is an orbivirus that is usually transmitted between its equid hosts by adult Culicoides midges. In this article, we review the ways in which AHSV may have adapted to this mode of transmission. The AHSV particle can be modified by the $\mathrm{pH}$ or proteolytic enzymes of its immediate environment, altering its ability to infect different cell types. The degree of pathogenesis in the host and vector may also represent adaptations maximising the likelihood of successful vectorial transmission. However, speculation upon several adaptations for vectorial transmission is based upon research on related viruses such as bluetongue virus (BTV), and further direct studies of AHSV are required in order to improve our understanding of this important virus.
\end{abstract}

\section{African horse sickness / AHSV / vector / Culicoides}

\section{Table of contents}

1. Introduction.

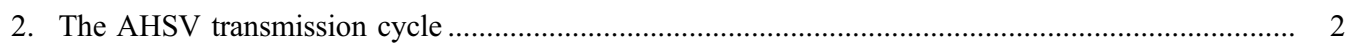

2.1. The transmission of vector-borne diseases........................................................................ 2

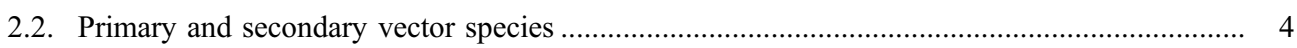

2.2.1. Culicoides vectors of AHSV ................................................................................. 4

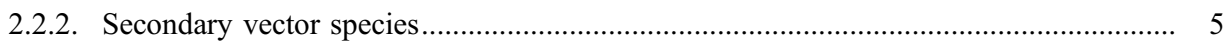

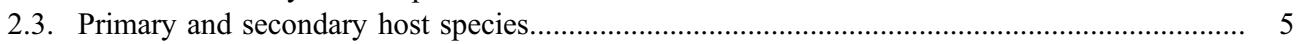

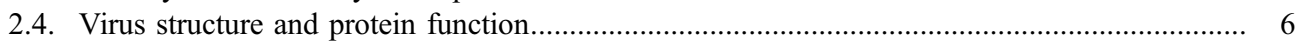

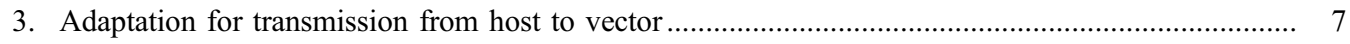

3.1. Generation of infectious sub-viral particles ................................................................. 7

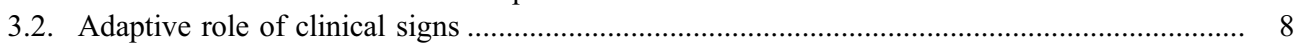

4. Adaptation for dissemination within the vector............................................................................. 9

4.1. Role of nonstructural proteins in cell exit and cytopathogenesis........................................... 9

4.2. Effects of temperature on the replication of AHSV …......................................................

5. Adaptation for transmission from vector to host ......................................................................... 10

6. Adaptation to periods of vector absence ........................................................................................ 11

7. Potential effects of tissue culture attenuation on epidemiology ...................................................... 11

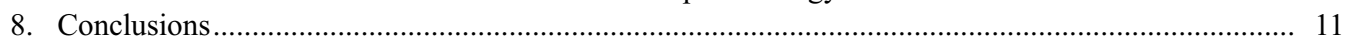

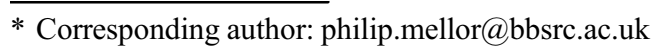




\section{INTRODUCTION}

African horse sickness virus (AHSV) is an orbivirus transmitted between equid hosts by Culicoides midges (Diptera, Ceratopogonidae). The clinical signs of AHSV infection are rarely seen in zebras and donkeys, but mortality rates can exceed $90 \%$ in horses. Although largely restricted to sub-Saharan Africa, AHSV has expanded beyond this core region on several occasions [24, 36], and has persisted for several years on each, suggesting that the geographical area that is potentially suitable for its transmission is considerably greater than that in which it currently occurs. As a consequence of its severity in horses and its proven capacity for sudden and rapid expansion, African horse sickness (AHS) is listed by the OIE as a notifiable disease.

Historical distribution and major outbreaks - Despite occasional small outbreaks in North Africa and the Arabian Peninsula, prior to 1959 AHSV was thought to be effectively confined to sub-Saharan Africa [75, 91]. During that year, AHSV-9 emerged in the Middle East, spreading as far as Pakistan and India [29, 36, 37, 75, 91]. This devastating outbreak caused the deaths of over 300000 equids before massive vaccination and vector control efforts, combined with the virtual extinction of susceptible hosts in the region, brought it to a halt in 1961 [4, 64]. Another outbreak caused by the same serotype occurred in North Africa during 1965 , and is thought to have originated from infected donkeys that were transported across the Sahara. This outbreak briefly spread as far north as southern Spain [23, 24, 43, 76]. In 1987, AHSV-4 was accidentally introduced into central Spain when infected zebras were imported for a safari park near Madrid [47], and remained active on the Iberian peninsula until 1990. More recently, in 2007, AHSV-4 was detected in Kenya and AHSV-2 and AHSV-7 were both detected in Senegal ${ }^{1}$, a country where serotype 9 has previously been detected [82]. This was the first time AHSV-2

\footnotetext{
${ }^{1}$ http://www.reoviridae.org/dsRNA_virus_proteins/ outbreaks.htm/
}

or AHSV-7 had been detected in West Africa. During 2007 the virus was also detected in Nigeria, Ghana, Mali and Mauritania.

Orbiviruses have spread from West Africa to the Iberian Peninsula on several occasions, probably via the transportation of infected adult Culicoides on the wind $[1,95,96]$. The circulation of AHSV in West Africa, combined with the rapid emergence of bluetongue virus (BTV) in Europe since 1998, and particularly the damage caused by BTV-8 since 2006 [114], suggests that the potential for Culicoides-borne orbiviruses to spread in Europe may be greater than previously appreciated. The recent spread of multiple AHSV serotypes to West Africa has further increased the risk of its introduction into Europe. In light of both these developments, an improved understanding of factors that can influence the distribution and spread of AHSV is urgently required. This paper reviews the ways in which AHSV is adapted to vector-borne transmission.

\section{THE AHSV TRANSMISSION CYCLE}

\subsection{The transmission of vector-borne diseases}

AHSV is a member of the genus Orbivirus in the family Reoviridae [74, 98, 99, 108]. The orbiviruses are predominantly transmitted via the bites of haematophagous arthropods, the main vectors being Culicoides midges, ticks, phlebotomine sandflies and mosquitoes [17, 67], while their vertebrate hosts include bats, equids, primates, ruminants, lagomorphs, and birds $[17,30]$. The biological transmission of AHSV by Culicoides vectors is illustrated in Figure 1.

For biological transmission by haematophagous arthropods, the virus must be present in peripheral blood vessels or in the skin tissues of the vertebrate host, making it accessible to blood-feeding arthropods. It must then survive in the environment of the arthropod gut long enough to penetrate and infect the cells of the gut wall. It must then finally spread through the internal environment of the arthropod to infect the salivary glands in order to be transmitted back to the vertebrate host during subsequent blood-feeding. The time between 


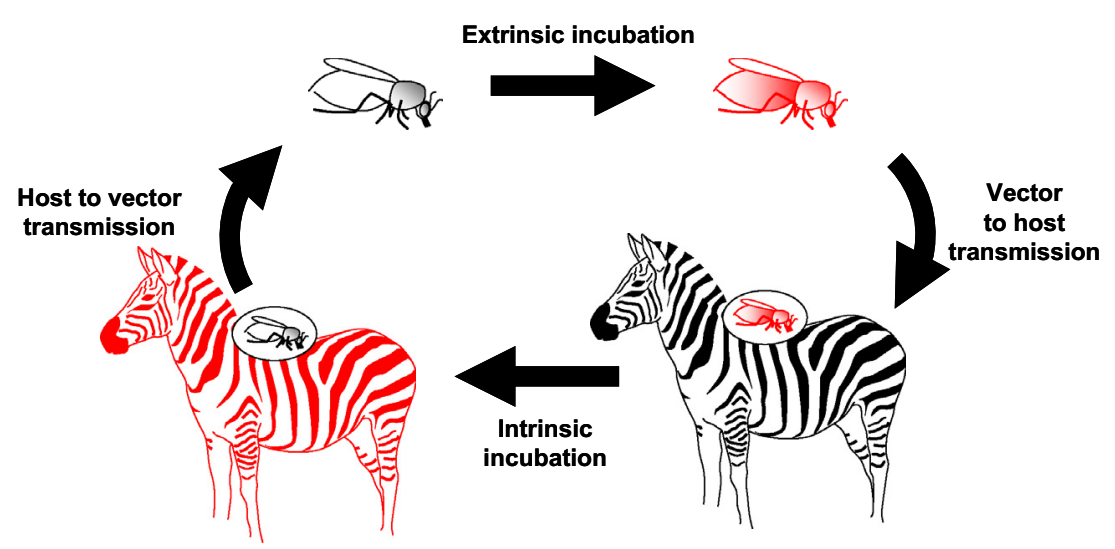

Figure 1. The AHSV transmission cycle. (A color version of this figure is available at www.vetres.org.)

ingestion and the insect being able to transmit the virus to another vertebrate host is termed the extrinsic incubation period (EIP), and is dependent upon the temperature experienced by the arthropod vector. In order for an infected arthropod to act as an effective vector, the virus must avoid causing significant pathogenesis during this stage, and the virus must also retain the ability to replicate in the vertebrate host.

Consequences for genetic diversity - The evolution and adaptation of vector-borne pathogens such as AHSV is constrained by a requirement to maintain viability under different conditions and retain the ability to infect very diverse cells within their mammalian hosts and arthropod vector species [20, 31]. However, variant genotypes inevitably arise during the processes of genome transcription and virus replication, while the small quantities of virus that are ingested and transmitted by small insects such as Culicoides represent a bottleneck that is likely to select a subset of the viral quasispecies present. This may lead to a particular variant or subpopulation becoming established as a novel genotype, a process that has been observed for BTV [13], and this "founder effect" is likely to play a significant role in establishing the genetic diversity of Culicoides-borne orbiviruses in the face of evolutionary constraints. Differences in cell and organ tropism, as well as antigenic selective pressure, may also help to determine the likelihood of certain strains being transmitted. This possibility is explored further in Section 3.2.

The infection of a host cell by two or more different strains belonging to the same Orbivirus species is likely to result in the generation of progeny viruses containing genome segments derived from both parental strains [72]. Reassortment is unique to segmented viruses such as AHSV, and provides a rapid mechanism for the generation of genetic diversity and subsequent virus evolution. Reassortment of RNA segments between orbivirus strains has been reported in vertebrate hosts, in insect vectors and in cell cultures [81, 94], with data suggesting that the rate of reassortment is higher in the insect $(42 \%)$ than in the vertebrate host $(5 \%)$.

Reassortment between different co-circulating viruses provides a mechanism allowing individual genome segments which confer a selective advantage within a particular ecosystem to rapidly spread and become established within the local virus population. Although relatively few sequence data are currently available for AHSV genome segments ${ }^{2}$, the global distribution of BTV is reflected by significant sequence variations in each of its genome segments between viruses from different geographic regions (e.g. the eastern and western topotypes described by Maan et al. [50]),

\footnotetext{
${ }^{2}$ http://www.reoviridae.org/dsRNA_virus_proteins
} 
and examples of both genome segment reassortment in the field and the establishment of specific variants of individual genome segments within a virus population are known for BTV [8]. These regional BTV variants are likely to have become established by reassortment, and as the geographical distribution of AHSV expands, the same mechanism may result in the rapid development of regional AHSV variants.

\subsection{Primary and secondary vector species}

\subsubsection{Culicoides vectors of $A H S V$}

AHSV is transmitted primarily by the bites of adult female Culicoides midges, which feed on blood to provide a protein source for egg production. Approximately 30 of the over 1500 identified species of Culicoides are believed to be capable of orbivirus transmission. The most important vector of AHSV in the field is Culicoides imicola, a species common throughout Africa and South East Asia. Although C. imicola was not identified in southern Europe until 1982 [14], earlier AHS outbreaks [23] suggest that it was probably already present in the region. C. imicola breeds in damp, organically enriched soil, and the adults feed opportunistically upon equids, ruminants and pigs [77]. In the AHSV-endemic areas of southern Africa, $C$. imicola typically accounts for $>90 \%$ of the Culicoides collected during light-trap surveillance in locations where AHSV (or BTV) are endemic, although it is less common in cooler highland regions [105]. The adult insects appear to be reluctant to enter enclosed buildings [85].

These characteristics of $C$. imicola have significant consequences for the epidemiology of imicola-transmitted AHSV. The nature of breeding sites suitable for $C$. imicola means that they are largely dependent on the level of rainfall, and heavy rains can significantly increase the abundance of adult Culicoides, in some cases up to 200-fold [59]. Major epizootics of AHS in South Africa are strongly associated with periods of heavy rain that are preceded by drought, a situation that also encourages susceptible hosts to congregate at watering holes, amplifying transmission further. These weather patterns are more common during the El Niño phase of the El Niño Southern Oscillation, and a statistical association between the latter and the occurrence of AHS outbreaks has been identified [9]. However, the relatively broad range of species targeted by $C$. imicola means that a proportion of infectious vectors will bite animals that are not susceptible to AHSV. The reluctance of $C$. imicola to enter enclosed spaces has also led to the widespread belief that stabling animals can substantially reduce AHSV transmission [85]. Recent work has implicated a second African species, Culicoides bolitinos, as a potential vector of AHSV [61]. C. bolitinos is morphologically very similar to C. imicola, and was only identified as a separate species in 1989 [58]. This species is widely distributed in southern Africa and is particularly common in the cooler highland areas, where C. imicola is rare $[61,106]$. C. bolitinos is also less reluctant to enter animal housing, potentially reducing the effectiveness of stabling as a method of limiting transmission in regions where it is a significant vector species [60].

Morphological similarities between adult Culicoides have hampered the identification of the European vectors of AHSV. Members of the Culicoides obsoletus and Culicoides pulicaris groups typically make up $>90 \%$ of the individuals collected during light-trap surveillance in northern Europe, and during the Spanish outbreak of AHS in 1987-1990, AHSV was isolated from mixed insect "pools" consisting almost entirely of midges from these Culicoides groups [63]. More recently, the C. obsoletus and C. pulicaris groups have also been implicated as European vectors of BTV [18]. However, the obsoletus group contains several distinct but morphologically indistinguishable species, which are likely to exhibit differences in their behaviour and vector capacity for these orbiviruses. Molecular techniques have recently been developed that can be used to distinguish individual species within each Culicoides group [55, 79], which will facilitate further studies of their vector competence.

The North American bluetongue vector Culicoides sonorensis can also be infected with 
AHSV and transmit it under laboratory conditions [62].

\subsubsection{Secondary vector species}

AHSV infection and transmission have been shown in some species of mosquitoes in the laboratory $[15,64,84]$, but they are generally considered to be of minor (if any) epidemiological significance as vectors in the field $[15,65$, 84]. AHSV has also been isolated from field samples of Hyalomma dromadarii ticks in Egypt $^{3,4}$, and further experiments demonstrated the possibility of transmission by this species to susceptible horses [5]. Since ticks have a relatively long lifespan compared to mosquitoes and Culicoides, it is possible that they could provide an effective reservoir for AHSV. However, as these experiments have not been repeated or confirmed, the role of ticks in the epidemiology of AHS remains uncertain, although most scientific opinion suggests that any role is likely to be small.

\subsection{Primary and secondary host species}

AHSV is capable of infecting all equids (i.e. horses, donkeys, asses and zebras). Zebra species are generally considered to be the natural vertebrate host, but rarely display clinical signs of infection. Historically, endemic transmission of the virus was thought to be limited to regions where zebra species occur. However, AHS epizootics have also occurred beyond the distribution of zebra species, in India and the Middle East, as well as in North Africa and the Iberian Peninsula, during 1959-1961, 1965-1966 and 1987-1990, caused by AHSV-9 and AHSV-4. Together with the continuing circulation of the virus (AHSV-2 and AHSV-7) in West Africa, this suggests that although zebra may represent

\footnotetext{
${ }^{3}$ Salama S.A., El-Husseini M.M., Abdulla S.K., Isolation and identification of African horse sickness virus in the camel tick, 3rd Annual Report, US AHS project Cairo, 1979.

${ }^{4}$ Salama S.A., El-Husseini M.M., Abdulla S.K., Isolation and identification of African horse sickness virus in the camel tick, 4th Annual Report, US AHS project Cairo, 1980.
}

important reservoir hosts, maintaining the virus in the field, they are not an essential part of the virus replication and transmission cycles. In view of the recent and rapid spread of BTV across Europe, this suggests that the distribution of AHSV also has the potential to expand dramatically in the near future, with devastating results.

The introduction of horses into central and east Africa during the 16th century resulted in the first detailed observations of AHS [102] and regular outbreaks have been reported from sub-Saharan Africa ever since. However, the frequency and extent of these outbreaks has declined over the last century, possibly as a result of the decline in wild zebra populations [68]. The extremely high mortality rate seen in horses limits the extent to which endemic transmission can occur in the species, and is believed to have been a major factor in bringing about the end of the 1959-1961 outbreak of AHSV-9 [4, 64]. It may also help to explain why the presence of an asymptomatic reservoir host such as zebra is an important factor for the endemic circulation of AHSV in the field. The AHSV viraemic period is considerably longer in zebras than in horses, and the decision to base quarantine regulations on the duration of viraemia in the latter was one of the causes of the accidental introduction of AHSV into Spain in 1987 [6].

In addition to equids, AHSV can infect certain carnivores via the ingestion of infected meat [2]. Antibodies to five different serotypes of AHSV have been detected in African carnivores [2], although these differed from those serotypes known to be circulating in the region at the time. Dogs infected with AHSV are capable of developing severe clinical disease, usually of the pulmonary kind, and frequently die from the infection. This pathology suggests that dogs develop AHSV viraemia, although its titre and duration are uncertain. However, AHSV transmission from a carnivore (dog, wild dog or big cat) has not been documented in the wild, and it is not known how frequently the Culicoides vectors of AHSV bite dogs, if at all. The role of carnivores in the transmission cycle of AHS therefore remains unclear, but it is considered likely that they 


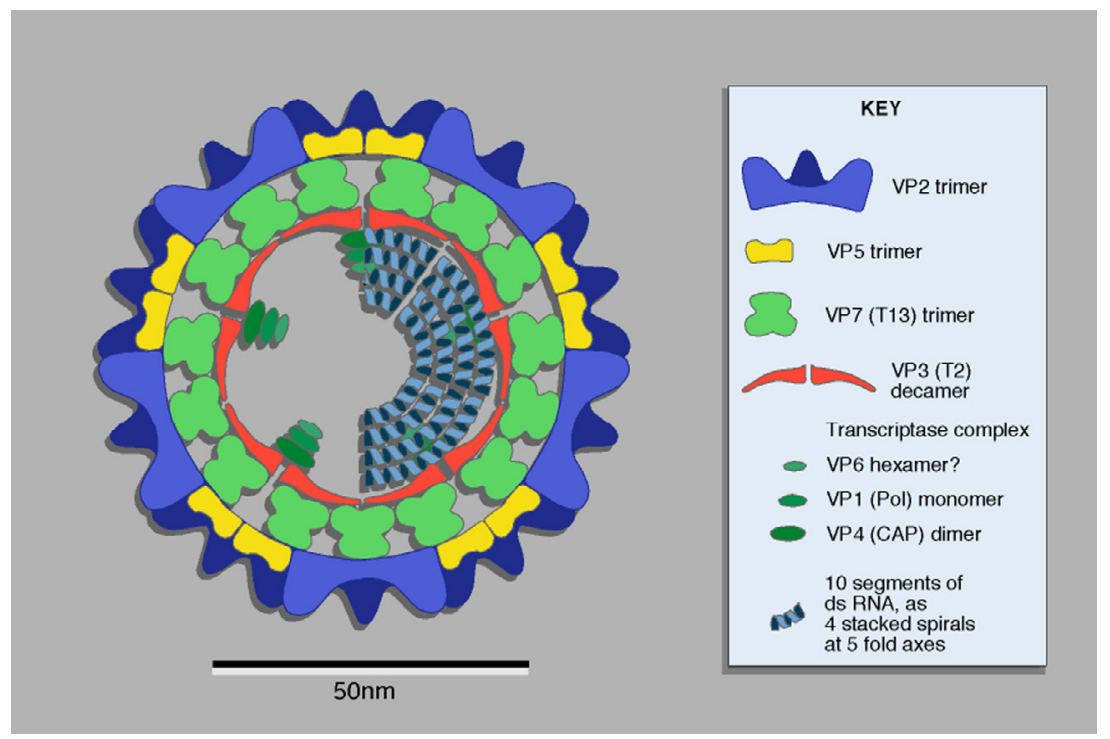

Figure 2. Diagram of orbivirus structure. Figure published in Virus Taxonomy: VIIIth Report of the International Committee on Taxonomy of Viruses, Mertens P.P.C., Attoui H., Duncan R., Dermody T.S. (Eds.), Reoviridae, pp. 447-454, (C) Elsevier. (A color version of this figure is available at www.vetres.org.)

act as dead-end hosts rather than as reservoirs of infection. AHSV antibodies have also been reported in elephants [11].

\subsection{Virus structure and protein function}

Like other orbiviruses, AHSV has a genome consisting of 10 segments of double-stranded RNA, which encode seven structural proteins (VP1-VP7) and four nonstructural proteins (NS1, NS2, NS3 and NS3a) [74]. The RNA genome is surrounded by the virus core, composed of an innermost "subcore" layer consisting of 120 copies of the VP3 protein, associated with minor structural proteins VP1, VP4 and VP6 [32]. The outer surface of the core is composed of 780 copies of VP7, which helps to stabilise the subcore layer [69]. In intact virus particles, this virus core is itself enclosed within an outer capsid of VP2 and VP5 trimers. This structure is shown in Figure 2.

Components of the outer capsid layer can be released from the AHSV core below $\mathrm{pH}$ 6. This is thought to occur in vivo within endosomes during the processes of infection and cell entry, activating the transcriptase activity of the virus core, which is released into the host-cell cytoplasm. Cleavage of VP2 in the AHSV outer capsid by trypsin or chymotrypsin generates infectious subviral particles (ISVP) [16]. The epidemiological significance of ISVP is discussed in Section 3.1.

The AHSV outer capsid proteins (VP2 and VP5) mediate cell attachment and penetration during the early stages of infection in mammalian cells. These proteins also determine the range of host cell types which the virus is able to infect, thereby influencing the sites of virus replication and tissues in which the virus is concentrated. Phylogenetic analyses have shown that the outer capsid proteins of BTV and epizootic haemorrhagic disease of deer virus are more closely related to each other than to those of AHSV [74], despite the overlapping geographic distribution of all three viruses. This may reflect adaptation to their respective hosts [112]. These proteins also determine the specificity of interactions between neutralising antibodies and the AHSV particle, and consequently control virus serotype [10, 21, 22, 49, 
$71,97]$. As a result, the genes encoding these proteins show substantial genetic variation, and the VP2 gene is the most variable segment of the orbivirus genome [49, 50]. Although VP2 is thought to contain most of the major serotype-determining antigens of AHSV, VP5 can also induce low levels of neutralising antibodies in the absence of VP2 [54].

VP7 forms the surface layer of the AHSV core. The finding that BTV core particles have a similar specific infectivity to that of intact virus particles for insect cells, but a drastically reduced infectivity for mammalian cells, suggests that core particles can also achieve cell attachment and entry of the virus in insect systems [117], possibly involving a distinct cell surface receptor from that used by VP2. However the increased infectivity of ISVP for adult Culicoides and insect cell cultures, compared to intact virus particles, suggests that they represent the primary route of infection in the vector insect.

The AHSV nonstructural proteins can be detected in the cytoplasm and membranes of infected cells [100]. NS1 forms tubular structures within the cell cytoplasm, while NS2 is a major component of the granular viral inclusion bodies that form within the cytoplasm of infected cells. NS3 can become glycosylated and is incorporated into the cell surface membrane. These NS proteins are believed to facilitate the processes of virus replication and cell exit. Their relevance in the context of adaptation to vectorial transmission is discussed in Section 4.1.

The AHSV NS3 gene is the second most variable after the segment encoding VP2 [104], although this is not true of all orbiviruses [50]. Because NS3 is associated with the membrane of infected cells and it is relatively exposed to the host immune system, its high variability may be partially due to selective pressure to avoid immune recognition [90]. However, based on findings in BTV, it has also been suggested that variability in nature of VP7 and NS3 may be partly due to their roles in the infection and release of virus particles from insect cells, and that this variability corresponds to genetic differences in the insects that the virus infects [50].

The remaining proteins (VP1, VP3, VP4 and VP6) are components of the virus subcore and appear to be largely concerned with the fundamental organisation, transcription, capping replication and packaging of the viral RNAs. They play a fundamental role in virus replication in both insect and mammalian cells, and may show variations or adaptations that are involved in transmission by the insect vector. For example, the activity of VP1, the RNA-dependent RNA polymerase, is highly dependent upon temperature, with an optimum between 27 and $42{ }^{\circ} \mathrm{C}$, and little or no activity below $12-15{ }^{\circ} \mathrm{C}$. Since insect vectors are ectothermic, the rate of viral RNA synthesis and therefore replication within the vector is largely governed by ambient temperature [115]. Variation in the genome segment coding for VP1 could therefore have important consequences for the geographic and seasonal distribution of AHSV transmission, influencing the duration and circumstances under which the EIP can be completed. This is discussed further in Section 4.2. However, all the core structural proteins are very highly conserved [50] and as a result are considered relatively unlikely to play a significant role in specific adaptation of the virus to vectorial transmission.

Variations in VP1, VP2, VP5, VP7 and nonstructural proteins NS1 and NS3 are considered most likely to influence the range of host and vector cell-types that can be infected by a specific orbivirus, the environmental conditions required for replication and transmission, the degree of pathogenesis resulting from infection, and the identity of the virus from the perspective of the vertebrate immune system. Adaptation of the virus for vectorial transmission is therefore likely to be largely restricted to the genome segments coding for these proteins.

\section{ADAPTATION FOR TRANSMISSION FROM HOST TO VECTOR}

\subsection{Generation of ISVP}

The exposure of intact AHSV particles to serine proteases results in the cleavage of VP2, generating two or more cleavage products that remain associated with the outer capsid 
Table I. Infectiousness of modified virus particle types relative to disaggregated virus. From data in [73]. "+" and "_" indicate differences of one log greater or lesser, respectively.

\begin{tabular}{lcccc}
\hline $\begin{array}{l}\text { Virus particle type } \\
\text { Cell type }\end{array}$ & Disaggregated virus & Aggregated virus & ISVP & Virus core \\
\hline BHK cell line (mammalian) & N/A & - & 0 & ----- \\
KC cell line (Culicoides) & N/A & - & ++ & - \\
\hline
\end{tabular}

layer of the particle [16]. The resulting ISVP has a similar infectivity for mammalian cell lines but greatly enhanced infectivity for C. sonorensis tissue culture cells (KC cells) [70]. BTV is also capable of forming ISVP [73]. Results obtained by immunogold labelling of BTV virus particles, by monoclonal antibodies to VP7, suggest that VP7 is not directly exposed at the surface of either virus particles or ISVP, unless the outer capsid proteins are further removed or modified ${ }^{5}$. The enhanced infectivity of ISVP may therefore reflect a change in receptor binding mediated by VP2, or increased efficiency of uncoating and exposure of VP7 during the early stages of infection and cell entry. The increased infectivity of ISVP has been confirmed in vivo by feeding adult Culicoides [52]. The relative infectivity of intact aggregated virus particles, ISVP and virus cores for mammalian and insect cells, compared to infectivity of disaggregated virus particles, is shown in Table I.

ISVP is generated by the exposure of intact virus particles to trypsin- or chymotrypsin-like proteases present in the saliva and gut of adult Culicoides [46]. AHSV exploits the unique environment it encounters at this stage of its transmission to increase its chances of infecting the insect gut wall, optimising the likelihood of its successful vectorial transmission. Chymotrypsin-like proteases which can cause cleavage of AHSV VP2 protein are also present in the blood of both horses and dogs, which may help to explain the host range of AHSV [52].

\footnotetext{
${ }^{5}$ Hutchinson I.R., The role of VP7 in initiation of infection by bluetongue virus, Ph.D. thesis, University of Hertfordshire, UK, 1999.
}

Finally, the saliva of competent and non competent Culicoides species appears to vary in the amount of protease activity that it contains, influencing the efficiency with which it converts intact virus to ISVP. A higher degree of VP2 cleavage occurs following incubation with saliva from $C$. sonorensis than from Culicoides nubeculosus (a non-vector species) ${ }^{6}$, possible due to a much lower level of trypsin in C. nubeculosus saliva. This suggests that vector competence may be partially determined by differences in the protein content of the insect's saliva, as well as by other factors.

\subsection{Adaptive role of clinical signs}

Following the initial infection of an equid host, AHSV initially multiplies in the regional lymph nodes before spreading to pulmonary microvascular endothelial cells [44]. Prominent pathological features of AHS (oedema, effusion and haemorrhage) suggest loss of endothelial cell-barrier function, in which NS3 protein may be involved [100]. Virus is then disseminated throughout the body via the bloodstream, infecting a range of secondary organs which may include the lungs, spleen, other lymphoid tissues, choroid plexus, pharynx and certain endothelial cells [19]. Replication in these organs produces a secondary viraemia, the duration and titre of which depends upon host species as well as other factors. Horses typically demonstrate high-titre viraemia for 4-8 days, while donkeys and zebras usually present lower

\footnotetext{
${ }^{6}$ Darpel K.E., The bluetongue virus "ruminant host-insect vector" transmission cycle; the role of Culicoides saliva proteins in infection, Ph.D. thesis, Royal Veterinary College, UK, 2007.
} 
levels of viraemia but for much longer periods of up to 28 days [19, 34].

Disease in the host can be classified according to the extent and severity of clinical signs into either acute (pulmonary), subacute (cardiac), mixed or febrile forms [19]. The clinical form of disease in horses varies according to the strain of virus causing the infection $[45,56,78]$. In the acute, subacute and mixed forms of AHS the virus is mainly localised in the cardio-vascular and lymphatic system, while in the febrile form of AHS the virus is concentrated in the spleen and almost absent from the lungs and heart. Strains isolated from the lungs of animals presenting the pulmonary form of the disease have been shown to be more virulent than isolates from the spleen [116], indicating that a quasispecies of viral strains with different virulence and organ tropisms can exist within a single infected equid host. The skin is directly involved as the site of transmission between the insect vector and equid host, and vice versa. It therefore represents a critical organ in the infection and transmission cycle of the virus (as discussed in Sect. 2.1), and as might be expected endothelial cells are one of the main locations in which viral antigen can be detected [116]. The ability of a viral strain to infect endothelial cells may therefore influence both the evolutionary fitness of a strain and the clinical form of disease ${ }^{7}$.

There are a number of further ways in which morbidity resulting from AHSV infection in the host might directly enhance the chance of successful transmission to a Culicoides vector. Infection by AHSV leads to increased vascular permeability and a reduction in the number of platelets in the blood, which could increase the probability of viral transmission to biting arthropods [42]. The development of a fever in an infected host may also enhance transmission, as febrile hosts may be more attractive to vector due to their elevated temperature. Finally, severe clinical signs in the host will reduce its ability to defend itself against vector attack.

\footnotetext{
${ }^{7}$ Erasmus B.J., The pathogenesis of African horse sickness, Proceedings of the 3rd International Conference on Equine Infectious Diseases, 1973, pp. 1-11.
}

\section{ADAPTATION FOR DISSEMINATION WITHIN THE VECTOR}

\subsection{Role of nonstructural proteins in cell exit and cytopathogenesis}

Orbivirus particles leave infected cells either by budding from the cell surface, or by lysis of the cell $[26,53]$. Insect cells become persistently infected, and virus exit only occurs via budding $[26,67]$, while lysis is the main mode of virus exit from infected mammalian cells [114]. The persistent nature of infection also demonstrates that shut-off of host-cell protein synthesis does not occur in Culicoides cells. This may help to prevent significant levels of cell damage and pathogenesis in the infected insect. Virus budding is mediated by NS3 [38], and this protein is expressed at higher levels in insect cells than mammalian cells [33, 38]. Suppression of NS1 protein drastically reduces the cytopathic effects of BTV infection in mammalian cells, suggesting that this protein is involved in cell lysis.

For vector-borne transmission to occur efficiently, a virus must avoid excessive pathogenesis in the vector, which must remain able to seek out new hosts for transmission to occur. At the same time, pathogenesis in the host may reduce its ability to notice or defend against vector attack as discussed in the previous section, and does not carry the same selective penalty. This difference in the dominant pathway of virus exit from infected cells is likely to be one of the factors responsible for the reduced pathogenic effects in the vector relative to the host, and therefore represents an adaptation for vectorial transmission.

\subsection{Effects of temperature on the replication of AHSV}

Temperature is the most important extrinsic variable affecting the rate of orbivirus replication within the insect vector (the EIP), primarily via its effects upon the activity of the viral RNA polymerase but also via its effects on the ability of the vector to modulate viral replication within its cells $[35,41]$. As temperature decreases, virogenesis slows and eventually 
effectively ceases. The lower threshold for AHSV replication in the Culicoides vector is approximately $15^{\circ} \mathrm{C}$ [115]. However, AHSV has been shown to persist in the vector at lower temperatures, in the absence of any detectable viral replication, and it can resume replication once the threshold temperature for virogenesis is reached [109]. Adult Culicoides can also survive for relatively prolonged periods in cold weather [48, 113], suggesting that AHSV could potentially survive short, mild winters in small numbers of long-lived midges. High temperatures may also disrupt the development of barriers to viral replication and dissemination, and a higher level of competence is seen in midges that are reared at high temperatures [66, 67].

It is now widely accepted that climate change has extended the distribution of BTV further north than ever before, both by extending the range of $C$. imicola and by enhancing the potential for transmission by suitable Palaearctic vectors (e.g. C. obsoletus group and C. pulicaris group) [89]. However, the dramatic northwards expansion of the European strain of BTV-8, while other serotypes have so far remained restricted to southern Europe, may indicate specific adaptation to replication in the more northerly ecosystem, or at cooler temperatures. This could have important implications for the future spread of the orbiviruses in Europe, particularly in light of the ability of orbiviruses to exchange segments (see Sect. 2.1).

\section{ADAPTATION FOR TRANSMISSION FROM VECTOR TO HOST}

AHSV must cross the barrier represented by the skin of the equid host twice during the course of a single transmission cycle. Skin is not only a mechanical barrier, but is also an immunologically active organ capable of initiating an immune response [40, 111]. However, arthropod saliva contains components that may be capable of inhibiting the host immunological response, modulating the local blood flow at the feeding site, and even promoting viral replication $[12,28,39,42,103]$. The epidemiological consequences of these effects have been collectively termed saliva activated transmission [92], and are likely to influence the transmission of orbiviruses such as AHSV by Culicoides. For example, the saliva of Culicoides inhibits the phagocytic activity of host macrophages at the site of biting [12], and has been shown to prevent blood coagulation and inflammation [87]. These and other effects of arthropod saliva on the host immune response may help to explain why infected Culicoides are able to transmit virus reliably with a single bite ${ }^{8}$, while a much larger amount of infectious virus is required for similar infection rates by needle inoculation [7, 12, 51]. Experimental transmission of some arboviruses via insect bite can result in greater and longer viraemia in animals than those where injection was used [83]. Although the immunomodulatory effects of arthropod saliva may benefit the transmission of vector-borne pathogens such as AHSV, there is thus far no evidence that such pathogens stimulate or enhance these effects, and they cannot therefore be said to represent an adaptation by the pathogen to transmission.

The introduction of orbiviruses into the skin of a naïve host is rapidly accompanied by a high level of viral replication and infection of both leukocytes and the microvascular epithelium of skin capillaries 9 . The recruitment of cellular components of the host immune system, as part of a hypersensitivity response to the Culicoides saliva proteins at the biting site, increases the likelihood of their infection and may play a part in the early stages of infection and dissemination within the mammalian host. The ability to infect cells attracted by this sensitivity response can therefore be regarded as an adaptation by the virus in order to enhance its transmission. It has also been suggested that local replication in the skin of an infected host may facilitate non-systemic transmission of viruses such as BTV or $\mathrm{AHSV}^{9}$, as demonstrated for other pathogens such as tick-borne

\footnotetext{
${ }^{8}$ O'Connell L., Entomological aspects of orbiviruses by Culicoides biting midges, Ph.D. thesis, University of Bristol, UK, 2002.

${ }^{9}$ Darpel K.E., The bluetongue virus "ruminant host-insect vector" transmission cycle; the role of Culicoides saliva proteins in infection, Ph.D. thesis, Royal Veterinary College, UK, 2007.
} 
encephalitis virus [93]. Culicoides are poolfeeders and may feed in large numbers on a single animal, which would increase the efficiency of this transmission route. However, there is no evidence so far of direct virus transmission between co-feeding Culicoides.

\section{ADAPTATION TO PERIODS OF VECTOR ABSENCE}

Throughout much of the range of AHSV, the climate is suitable for adult Culicoides to remain active throughout the year. However, in some areas, conditions can be unsuitable during parts of the year for the emergence or activity of adult Culicoides, or temperatures may be too low for the virus to replicate in the vector. Despite these interruptions in normal transmission, AHSV and BTV are still able to persist for long periods during adverse climatic conditions without the observation of new cases. This phenomenon is termed "overwintering". In some cases these absences can last for up to $11 \frac{1}{2}$ months and have resulted in false assumptions that an outbreak has ended $[3,25]$.

A number of different mechanisms could potentially be involved in orbivirus overwintering [113]. Persistent or chronic AHSV infection in horses is considered unlikely, as viraemia is short and mortality rates frequently exceed $90 \%$. However, zebras display a detectable viraemia for up to 40 days post-infection, while virus could be recovered from tissues and cells for up to 48 days [6]. Donkeys, meanwhile, fit between these two extremes, typically displaying a viraemia for up to 4 weeks and a mortality rate of around $10 \%$ [19]. There is a possibility that latently-infected animals may represent a mechanism of overwintering, following the discovery of a similar mechanism in the case of BTV-infected sheep [101], although there is currently no evidence that AHSV has adapted to seasonal vector absence in a similar way. Other routes such as transplacental transmission have been implicated for BTV, but the relevance of these routes (if any) to the overwintering of AHSV remains unknown. Finally, although it would represent a highly advantageous adaptation to the seasonal absence of adult vectors, there is no evidence that vertical transmission of AHSV is likely to occur in the insect vector, with studies suggesting that pores in the membrane surrounding the developing egg mechanically prevent intact virus particles from entering it [80], while allowing fragments of RNA to pass through [110]. To summarise, few of the possible mechanisms for orbivirus overwintering have been conclusively demonstrated, and many are highly speculative. It is also possible that the mechanisms responsible vary by region or virus strain.

\section{POTENTIAL EFFECTS OF TISSUE CULTURE ATTENUATION ON EPIDEMIOLOGY}

The repeated passage of a virus through vertebrate cell lines (tissue culture attenuation), which is a procedure frequently undertaken in the production of live attenuated vaccines, might be expected to reduce or remove its ability to replicate in vector insects. However, the work of Paweska et al. [86], when working with AHSV serotypes 1, 2, 3, 4, 6, 7 and 8, has shown that such attenuation does not necessarily eliminate a virus's capability to infect $C$ ulicoides vectors, and more recent work [107] suggests that tissue culture attenuation of AHSV might even lead to enhanced replication in vectors. Other changes may also be conferred upon viruses manipulated in this way, and Gibbs et al. [27] have shown that tissue culture attenuated strains of the related BTV are able to be transmitted transplacentally from dam to foetus in the vertebrate host. As far as we are aware there are no experimental data to indicate whether tissue culture passaged AHSV can, or cannot be transmitted transplacentally.

\section{CONCLUSIONS}

Vector-borne transmission is a highly complex process. It requires virus to be located in the peripheral blood vessels or skin of the vertebrate host, to tolerate the proteolytic environment of the arthropod gut, and to be able to spread from the gut of the arthropod to the salivary glands, while at the same time minimising the damage caused to the arthropod vector. 
Despite this, AHSV has successfully adapted to transmission between equid hosts by Culicoides midges in the apparent absence of alternative transmission mechanisms. The AHSV particle can be modified by $\mathrm{pH}$ or proteases in its immediate environment, and appears to have adapted to make use of these changes during transmission. AHSV also appears to manipulate the extent of pathogenesis in the host and vector to maximise the likelihood of its successful transmission. However, speculation upon several potential adaptations for successful vectorial transmission is based upon research on related viruses such as BTV, and further direct study of AHSV is required.

Several aspects of the epidemiology of AHSV indicate that it represents a significant risk to Europe and North America. Although it is currently restricted to sub-Saharan Africa, it has expanded beyond this core region on several occasions, demonstrating a capacity to persist in these regions for several years [4, 64]. This suggests that the geographical area potentially suitable for AHSV transmission is considerably greater than that in which it is currently found. The recent expansion of BTV into northern Europe also supports this conclusion. Both the 1965 and 1987 AHS outbreaks were traced to the importation of sub-clinically infected equids $[47,57,88]$ suggesting that animal movements represent an important route of AHSV introduction into new regions. This risk could be reduced by strict adherence to appropriate international trade regulations. Adaptations which reduce the frequency or severity of clinical signs could paradoxically increase the global risk from the disease by making the detection of infected individuals more difficult and accidental introduction more likely. Like BTV, AHSV is capable of persisting in an area for long periods of time without the appearance of new cases, a phenomenon termed "overwintering". This is likely to complicate the eradication of AHSV outbreaks, as well as verifying the success of eradication programmes.

In order to be capable of accurately assessing risk from AHSV, we need to further improve our understanding of how variations in the virus can alter its capacity to infect and cause clinical signs in different host species, as well as influencing its transmission between Culicoides vectors and equid hosts in different ecosystems and under different environmental conditions.

Acknowledgements. The authors would like to thank Dr Karin Darpel for helpful discussion of saliva-mediated transmission and other topics described in this paper. This work was funded by the Biotechnology and Biological Sciences Research Council (grant numbers BBS/B/00603, BB/F00852X/1, BB/D014204/1 and strategic core grants 1144, 1146); and the UK Department for Environment, Food and Rural Affairs (grant numbers SE2616, SE2613, SE4104).

\section{REFERENCES}

[1] Alba A., Casal J., Domingo M., Possible introduction of bluetongue into the Balearic Islands, Spain, in 2000, via air streams, Vet. Rec. (2004) 155:460-461.

[2] Alexander K.A., Kat P.W., House J., O’Brien S.J., Laurenson M.K., McNutt J.W., Osburn B.I., African horse sickness and African carnivores, Vet. Microbiol. (1995) 47:133-140.

[3] Anonymous, Status of African horse sickness (AHS), Bull. Off. Int. Epizoot. (1987) 99:46-48.

[4] Anwar M., Qureshi A., Control and eradication of African horse sickness in Pakistan, in: Control and eradication viral diseases in the CENTO region, Ankara, Central Treaty Organisation, 1972, pp. $110-112$.

[5] Awad F.I., Amin M.M., Salama S.A., Khide S., The role played by Hyalomma dromedarii in the transmission of African horse sickness in Egypt, Bull. Anim. Health Prod. Afr. (1981) 29:337-340.

[6] Barnard B.J.H., Bengis R., Keet D., Dekker E.H., Epidemiology of African horsesickness - duration of viremia in zebra (Equus burchelli), Onderstepoort J. Vet. Res. (1994) 61:391-393.

[7] Barratt-Boyes S.M., MacLachlan N.J., Dynamics of viral spread in bluetongue virus infected calves, Vet. Microbiol. (1994) 40:361-371.

[8] Batten C.A., Maan S., Shaw A.E., Maan N.S., Mertens P.P.C., A European field strain of bluetongue virus derived from two parental vaccine strains by genome segment reassortment, Virus Res. (2008) 137:56-63.

[9] Baylis M., Mellor P.S., Meiswinkel R., Horse sickness and ENSO in South Africa, Nature (1999) 397:574

[10] Bentley L., Fehrsen J., Jordaan F., Huismans H., Du Plessis D.H., Identification of antigenic regions on VP2 of African horsesickness virus serotype 3 by using phage-displayed epitope libraries, J. Gen. Virol. (2000) 81:993-1000. 
[11] Binepal V.S., Wariru B.N., Davies F.G., Soi R., Olubayo R., An attempt to define the host range for African horse sickness virus (Orbivirus, Reoviridae) in East Africa, by a serological survey in some Equidae, Camelidae, Loxodontidae and Carnivora, Vet. Microbiol. (1992) 31:19-23.

[12] Bishop J.V., Mejia J.S., Perez de Leon A.A., Tabachnick W.J., Titus R.G., Salivary gland extracts of Culicoides sonorensis inhibit murine lymphocyte proliferation and no production by macrophages, Am. J. Trop. Med. Hyg. (2006) 75:532-536.

[13] Bonneau K.R., Mullens B.A., MacLachlan N.J., Occurrence of genetic drift and founder effect during quasispecies evolution of the VP2 and NS3/NS3A genes of bluetongue virus upon passage between sheep, cattle, and Culicoides sonorensis, J. Virol. (2001) 75:8298-8305.

[14] Boorman J.P.T., Wilkinson P.J., Potential vectors of bluetongue in Lesbos, Greece, Vet. Rec. (1983) 113:395-396.

[15] Braverman Y., Boorman J., Rates of infection in, and transmission of, African horse sickness virus by Aedes aegypti mosquitoes, Acta Virol. (1978) 22:329-332.

[16] Burroughs J.N., O’Hara R.S., Smale C.J., Hamblin C., Walton A., Armstrong R., Mertens P.P.C., Purification and properties of virus particles, infectious subviral particles, cores and VP7 crystals of African horsesickness virus serotype 9, J. Gen. Virol. (1994) 75:1849-1857.

[17] Calisher C.H., Mertens P.P., Taxonomy of African horse sickness viruses, Arch. Virol. Suppl. (1998) 14:3-11.

[18] Carpenter S., Lunt H.L., Arav D., Venter G.J., Mellor P.S., Oral susceptibility to bluetongue virus of Culicoides (Diptera : Ceratopogonidae) from the United Kingdom, J. Med. Entomol. (2006) 43:73-78.

[19] Coetzer J., Erasmus B., African horse sickness, in: Coetzer J., Thomson G., Tustin R. (Eds.), Infectious diseases of livestock with special reference to Southern Africa, Cape Town, Oxford University Press, 1994, pp. 460-475

[20] Coffey L.L., Vasilakis N., Brault A.C., Powers A.M., Tripet F., Weaver S.C., Arbovirus evolution in vivo is constrained by host alternation, Proc. Natl. Acad. Sci. USA (2008) 105:6970-6975.

[21] Cowley J.A., Gorman B.M., Cross-neutralization of genetic reassortants of bluetongue virus serotypes 20 and 21, Vet. Microbiol. (1989) 19:37-51.

[22] DeMaula C.D., Bonneau K.R., MacLachlan N.J., Changes in the outer capsid proteins of bluetongue virus serotype ten that abrogate neutralization by monoclonal antibodies, Virus Res. (2000) 67:59-66.

[23] Diaz Montilla R., Panos Marti P., Epizootologia de la peste equina en Espana, Bull. Off. Int. Epizoot. (1967) 86:705-714.
[24] Diaz Montilla R., Panos Marti P., La peste Equina, Bull. Off. Int. Epizoot. (1968) 70:647-662.

[25] Diaz Yubero M., Epizootiological Inf. No. ESP. 87/6/145, 1987

[26] Fu H., Leake C.J., Mertens P.P., Mellor P.S., The barriers to bluetongue virus infection, dissemination and transmission in the vector, Culicoides variipennis (Diptera: Ceratopogonidae), Arch. Virol. (1999) 144:747-761.

[27] Gibbs E.P.J., Lawman M.J.P., Herniman K.A.J., Preliminary observations on transplacental infection of bluetongue virus in sheep - a possible overwintering mechanism, Res. Vet. Sci. (1979) 27:118-120.

[28] Gillespie R.D., Mbow M.L., Titus R.G., The immunomodulatory factors of bloodfeeding arthropod saliva, Parasite Immunol. (2000) 22:319-331.

[29] Gohre D., Khot J., Paranjpe V., Manjrekar S., Observations on the outbreak of South African horse sickness in India during 1960-1961, Bombay Vet. Coll. Mag. (1964-1965) 5-15.

[30] Gould A.R., Hyatt A.D., The orbivirus genus. Diversity, structure, replication and phylogenetic relationships, Comp. Immunol. Microbiol. Infect. Dis. (1994) 17:163-188.

[31] Greene I.P., Wang E.Y., Deaddorff E.R., Milleron R., Domingo E., Weaver S.C., Effect of alternating passage on adaptation of sindbis virus to vertebrate and invertebrate cells, J. Virol. (2005) 79:14253-14260.

[32] Grubman M., Lewis S., Identification and characterisation of the structural and non-structural proteins of African horse sickness virus and determination of the genome coding assignments, Virology (1992) 186:444-451.

[33] Guirakhoo F., Catalan J.A., Monath T.P., Adaptation of bluetongue virus in mosquito cells results in overexpression of NS3 proteins and release of virus particles, Arch. Virol. (1995) 140:967-974.

[34] Hamblin C., Salt J., Mellor P.S., Graham S., Smith P., Wohlsein P., Donkeys as reservoirs of African horse sickness, Arch. Virol. (1998) Suppl. $14: 37-47$.

[35] Hardy J.L., Houk E.J., Kramer L.D., Reeves W.C., Intrinsic factors affecting vector competence of mosquitoes for arboviruses, Ann. Rev. Entomol. (1983) 28:229-262.

[36] Howell P., The 1960 epizootic in the Middle East and SW Asia, J. S. Afr. Vet. Assoc. (1960) 31:329-334.

[37] Howell P., African horse sickness, in: Emerging diseases of animals, FAO Agricultural Studies No. 61, Rome, FAO, 1963, pp. 71-108.

[38] Hyatt A.D., Zhao Y., Roy P., Release of bluetongue virus-like particles from insect cells is mediated by BTV nonstructural protein NS3/NS3A, Virology (1993) 193:592-603. 
[39] Jones L.D., Hodgson E., Williams T., Higgs S., Nuttall P.A., Saliva activated transmission (SAT) of Thogoto virus: relationship with vector potential of different haematophagous arthropods, Med. Vet. Entomol. (1992) 6:261-265.

[40] Kapsenberg M.L., Teunissen M.B.M., Bos J.D., Langerhans cells: a unique subpopulation of antigen presenting dendritic cells, in: Bos J.D. (Ed.), Skin Immune System (SIS), Boca Raton, Florida, CRC Press, 1990, pp. 109-124.

[41] Kramer L.D., Hardy J.L., Presser S.B., Effect of temperature of extrinsic incubation on the vector competence of Culex tarsalis for western equine encephalomyelitis virus, Am. J. Trop. Med. Hyg. (1983) 32:1130-1139.

[42] Kuno G., Chang G.-J.J., Biological transmission of arboviruses: reexamination of and new insights into components, mechanisms and unique traits as well as their evolutionary trends, Clin. Microbiol. Rev. (2005) 18:608-637.

[43] Laaberki A., Évolution d'une épizootie de peste équine africaine au Maroc, Bull. Off. Int. Epizoot. (1969) 71:921-936.

[44] Laegreid W.W., Burrage T.G., Stone-Marschat M., Skowronek A., Electron microscopic evidence for endothelial infection by African horsesickness virus, Vet. Pathol. (1992) 29:554-556.

[45] Laegreid W.W., Skowronek A., Stone-Marschat M., Burrage T., Characterization of virulence variants of African horsesickness virus, Virology (1993) 195: 836-839.

[46] Langner K.F., Darpel K.E., Denison E., Drolet B.S., Leibold W., Mellor P.S., et al., Collection and analysis of salivary proteins from the biting midge Culicoides nubeculosus (Diptera: Ceratopogonidae), J. Med. Entomol. (2007) 44:238-248.

[47] Lubroth J., African horse sickness and the epizootic in Spain 1987, Equine Pract. (1988) 10:26-33.

[48] Lysyk T.J., Danyk T., Effect of temperature on life history parameters of adult Culicoides sonorensis (Diptera: Ceratopogonidae) in relation to geographic origin and vectorial capacity for bluetongue virus, J. Med. Entomol. (2007) 44:741-751.

[49] Maan S., Maan N.S., Samuel A.R., Rao S., Attoui H., Mertens P.P.C., Analysis and phylogenetic comparisons of full-length VP2 genes of the 24 bluetongue virus serotypes, J. Gen. Virol. (2007) 88:621-630.

[50] Maan S., Maan N.S., Ross-Smith N., Batten C.A., Shaw A.E., Anthony S.J., et al., Sequence analysis of bluetongue virus serotype 8 from the Netherlands 2006 and comparison to other European strains, Virology (2008) 377:308-318.

[51] MacLachlan N.J., Jagels G., Rossitto P.V., Moore P.F., Heidner H.W., The pathogenesis of experimental bluetongue virus infection of calves, Vet. Pathol. (1990) 27:223-229.

[52] Marchi P.R., Rawlings P., Burroughs J.N., Wellby M.P., Mertens P.P.C., Mellor P.S., Wade-Evans A.M., Proteolytic cleavage of VP2, an outer capsid protein of African horse sickness virus, by speciesspecific serum proteases enhances infectivity in Culicoides, J. Gen. Virol. (1995) 76:2607-2611.

[53] Martin L.A., Meyer A.J., O’Hara R.S., Fu H., Mellor P.S., Knowles N.J., Mertens P.P., Phylogenetic analysis of African horse sickness virus segment 10: sequence variation, virulence characteristics and cell exit, Arch. Virol. Suppl. (1998) 14:281-293.

[54] Martinez-Torrecuadrada J.L., Langeveld J.P., Venteo A., Sanz A., Dalsgaard K., Hamilton W.D., et al., Antigenic profile of African horse sickness virus serotype 4 VP5 and identification of a neutralizing epitope shared with bluetongue virus and epizootic hemorrhagic disease virus, Virology (1999) 257: 449-459.

[55] Mathieu B., Perrin A., Baldet T., Delecolle J.-C., Albina E., Cêtre-Sossah C., Molecular identification of western European species of Obsoletus complex (Diptera: Ceratopogonidae) by an internal transcribed spacer-1 rDNA multiplex polymerase chain reaction assay, J. Med. Entomol. (2007) 44:1019-1025.

[56] Maurer F.D., McCully R.M., African horse sickness, with emphasis on pathology, Am. J. Vet. Res. (1963) 24:235-266.

[57] Maurice Y., Provost A., La peste équine a type 9 en Afrique Centrale enquête sérologique, Rev. Elev. Med. Vet. Pays Trop. (1967) 20:21-25.

[58] Meiswinkel R., Afro-tropical Culicoides - a redescription of Culicoides (Avaritia) imicola Kieffer, 1913 (Diptera: Ceratopogonidae) with description of the closely allied Culicoides (Avaritia) bolitinos sp.nov. reared from the dung of the African buffalo, blue windebeest and cattle in South Africa, Onderstepoort J. Vet. Res. (1989) 56:23-39.

[59] Meiswinkel R., Nevill E., Venter G., Vectors: Culicoides spp., in: Coetzer J., Thomson G.,Tustin R. (Eds.), Infectious diseases of livestock with special reference to Southern Africa, Cape Town, Oxford University Press, 1994, pp. 68-89.

[60] Meiswinkel R., Baylis M., Labuschagne K., Stabling and the protection of horses from Culicoides bolitinos (Diptera: Ceratopogonidae), a recently identified vector of African horse sickness, Bull. Entomol. Res. (2000) 90:509-515.

[61] Meiswinkel R., Paweska J.T., Evidence for a new field Culicoides vector of African horse sickness in South Africa, Prev. Vet. Med. (2003) 60: 243-253.

[62] Mellor P.S., Boorman J., Jennings M., The multiplication of African horse sickness virus in two 
species of Culicoides (Diptera, Ceratopogonidae), Arch. Virol. (1975) 47:351-356.

[63] Mellor P.S., Boned J., Hamblin C., Graham S., Isolations of African horse sickness virus from vector insects made during the 1988 epizootic in Spain, Epidemiol. Infect. (1990) 105:447-454.

[64] Mellor P.S., African horse sickness: transmission and epidemiology, Vet. Res. (1993) 24:199-212.

[65] Mellor P.S., Epizootiology and vectors of African horse sickness virus, Comp. Immunol. Microbiol. Infect. Dis. (1994) 17:287-296.

[66] Mellor P.S., Rawlings P., Baylis M., Wellby M.P., Effect of temperature on African horse sickness virus infection in Culicoides, Arch. Virol. (1998) Suppl. 14:155-163.

[67] Mellor P.S., Replication of arboviruses in insect vectors, J. Comp. Pathol. (2000) 124:231-247.

[68] Mellor P.S., Hamblin C., African horse sickness, Vet. Res. (2004) 35:445-466.

[69] Mellor P.S., Mertens P.P.C., African horse sickness viruses, Encyclopedia of Virology, 2008, pp. 37-43.

[70] Mertens P.P., Burroughs J.N., Anderson J., Purification and properties of virus particles, infectious subviral particles, and cores of bluetongue virus serotypes 1 and 4, Virology (1987) 157:375-386.

[71] Mertens P.P., Pedley S., Cowley J., Burroughs J.N., Corteyn A.H., Jeggo M.H., et al., Analysis of the roles of bluetongue virus outer capsid proteins VP2 and VP5 in determination of virus serotype, Virology (1989) 170:561-565.

[72] Mertens P.P.C., Orbiviruses and coltiviruses I. General features, Encyclopedia of Virology, 1994, pp. 941-964.

[73] Mertens P.P.C., Burroughs J.N., Walton A., Wellby M.P., Fu H., O'Hara R.S., et al., Enhanced infectivity of modified bluetongue virus particles for two insect cell lines and for two Culicoides vector species, Virology (1996) 217:582-593.

[74] Mertens P.P.C., Maan S., Samuel A., Attoui H., Orbivirus, Reoviridae, in: Fauquet C.M., Mayo M.A., Maniloff J., Desselberger U., Ball L.A. (Eds.), Virus Taxonomy, VIIIth Report of the ICTV, London, Academic Press, 2005, pp. 466-483.

[75] Mirchamsy H., Hazrati A., A review of the aetiology and pathology of African horse sickness, Arch. Hessarek Iran (1973) 25:23-46.

[76] Mornet P., Toma B., Sers J., Une nouvelle maladie réputée légalement contagieuse: la peste équine, Rec. Med. Vet. Ec. Alfort (1967) 143:119-139.

[77] Nevill E., Anderson D., Host preferences of Culicoides midges (Diptera: Ceratopogonidae) in South Africa as determined by precipitin tests and light trap catches, Onderstepoort J. Vet. Res. (1972) 39:147-152.
[78] Newsholme S.J., A morphological study of the lesions of African horsesickness, Onderstepoort J. Vet. Res. (1983) 50:7-24.

[79] Nolan D.V., Carpenter S., Barber J., Mellor P.S., Dallas J.F., Mordue J.A., Piertney S.B., Rapid diagnostic PCR assays for members of the Culicoides obsoletus and Culicoides pulicaris species complexes, implicated vectors of bluetongue virus in Europe, Vet. Microbiol. (2007) 124:82-94.

[80] Nunamaker R.A., Sieburth P.J., Dean V.C., Wigington J.G., Nunamaker C.E., Mecham J.O., Absence of transovarial transmission of bluetongue virus in Culicoides variipennis: immunogold labelling of bluetongue virus antigen in developing oocytes from Culicoides variipennis (Coquillett), Comp. Biochem. Physiol. A (1990) 96:19-31.

[81] O’Hara R.S., Meyer A.J., Burroughs J.N., Pullen L., Martin L.A., Mertens P.P.C., Development of a mouse model system and identification of individual genome segments of African horse sickness virus, serotypes 3 and 8 involved in determination of virulence, Arch. Virol. (1998) S14:259-279.

[82] Office International des Épizooties, African Horse sickness, Senegal (2007).

[83] Osorio J.E., Godsey M.S., Defoliart G.R., Yuill T.M., La Crosse viremias in white-tailed deer and chipmunks exposed by injection or mosquito bite, Am. J. Trop. Med. Hyg. (1996) 54:338-342.

[84] Ozawa Y., Nakata G., Experimental transmission of African horse sickness by means of mosquitoes, Am. J. Vet. Res. (1965) 26:744-748.

[85] Paton T., The "horse sickness" of the Cape of Good Hope, Veterinarian (1863) 36:489-494.

[86] Paweska J.T., Prinsloo S., Venter G.J., Oral susceptibility of South African Culicoides species to live-attenuated serotype-specific vaccine strains of African horse sickness virus (AHSV), Med. Vet. Entomol. (2003) 17:436-447.

[87] Perez de Leon A.A., Valenzuela J.G., Tabachnick W.J., Anticoagulant activity in salivary glands of the insect vector Culicoides variipennis sonorensis by an inhibitor of factor Xa, Exp. Parasitol. (1998) 88:121-130.

[88] Pilo-Moron E., Vincent J., Ait-Mesbah O., Forthomme G., Origine de la peste équine en Afrique du Nord; résultats d'une enquête sur les ânes du Sahara algérien, Arch. Inst. Pasteur Alger (1969) 47:105-118.

[89] Purse B.V., Mellor P.S., Rogers D.J., Samuel A.R., Mertens P.P.C., Baylis M., Climate change and the recent emergence of bluetongue in Europe, Nat. Rev. Microbiol. (2005) 3:171-181.

[90] Quan M., van Vuuren M., Howell P.G., Groenewald D., Guthrie A.J., Molecular epidemiology of the 
African horse sickness virus S10 gene, J. Gen. Virol. (2008) 89:1159-1168

[91] Rafyi A., Horse sickness, Bull. Off. Int. Epizoot. (1961) 56:216-250.

[92] Randolph S.E., Nuttall P.A., Nearly right or precisely wrong? Natural versus laboratory studies of vector-borne diseases, Parasitol. Today (1994) 10:458-462.

[93] Randolph S.E., Gern L., Nuttall P.A., Co-feeding ticks: epidemiological significance for tick-borne pathogen transmission, Parasitol. Today (1996) 12:472-479.

[94] Roy P., Marshall J.J.A., French T.J., Structure of bluetongue virus genome and its encoded proteins, Curr. Top. Microbiol. Immunol. (1990) 162:43-87.

[95] Sellers R.F., Pedgeley D.E., Tucker M.R., Possible spread of African horse sickness on the Wind, J. Hyg. (London) (1977) 79:279-298.

[96] Sellers R.F., Pedgeley D.E., Tucker M.R., Possible windborne spread of bluetongue to Portugal, June-July 1956, J. Hyg. (London) (1978) 81:189-196.

[97] Singh K.P., Maan S., Samuel A., Rao S., Meyer A.J., Mertens P.P.C., Phylogenetic analysis of bluetongue virus genome segment 6 (encoding VP5) from different serotypes, Vet. Ital. (2005) 40:479-483.

[98] Spence R., Moore N., Nuttal P., The biochemistry of orbiviruses, Arch. Virol. (1984) 82:1-18.

[99] Stanley N., Reoviridae: Orbivirus and reovirus infections of mammals and birds, In: Kurstak E., Kurstak C. (Eds.), Comparative Diagnosis of Viral Diseases, New York, Academic Press, 1981, pp. 67-104.

[100] Stoltz M.A., van der Merwe C.F., Coetzee J., Huismans H., Subcellular localization of the nonstructural protein NS3 of African horsesickness virus, Onderstepoort J. Vet. Res. (1996) 63:57-61.

[101] Takamatsu H., Mellor P.S., Mertens P.P.C., Kirkham P.A., Burroughs J.N., Parkhouse R.M.E., A possible overwintering mechanism for bluetongue virus in the absence of the insect vector, J. Gen. Virol. (2003) 84:227-235.

[102] Theal G., Records of South-Eastern Africa collected in various libraries and archive departments in Europe, Government of Cape Colony (1899) 3:224.

[103] Titus R.G., Ribeiro J.M., The role of vector saliva in transmission of arthropod-borne disease, Parasitol. Today (1990) 6:157-160.

[104] Van Niekerk M., Smit C.C., Fick W.C., van Staden V., Huismans H., Membrane association of African horsesickness virus nonstructural protein NS3 determines its cytotoxicity, Virology (2001) 279: 499-508.

[105] Venter G.J., Meiswinkel R., The virtual absence of Culicoides imicola (Diptera: Ceratopogonidae) in a light-trap survey of the colder, high-lying area of the eastern Orange Free State, South Africa, and implications for the transmission of arboviruses, Onderstepoort J. Vet. Res. (1994) 61:327-340.

[106] Venter G.J., Graham S., Hamblin C., African horse sickness epidemiology: vector competence of South African Culicoides species for virus serotypes 3, 5 and 8, Med. Vet. Entomol. (2000) 14:245-250.

[107] Venter G.J., Paweska J.T., Virus recovery rates for wild-type and live-attenuated vaccine strains of African horse sickness virus serotype 7 in orally infected South African Culicoides species, Med. Vet. Entomol. (2007) 21:377-383.

[108] Verwoerd D., Huismans H., Erasmus B., Orbiviruses, in: Fraenkel-Conrat H., Wagner R. (Eds.), Comprehensive virology, London, Plenum Press, 1979, pp. 285-345.

[109] Wellby M.P., Baylis M., Rawlings P., Mellor P.S., Effect of temperature on survival and rate of virogenesis of African horse sickness virus in Culicoides variipennis sonorensis (Diptera: Ceratopogonidae) and its significance in relation to the epidemiology of the disease, Bull. Entomol. Res. (1996) 86:715-720.

[110] White D.M., Wilson W.C., Blair C.D., Beaty B.J., Studies on overwintering of bluetongue viruses in insects, J. Gen. Virol. (2005) 86:453-462.

[111] Wikel S.K., Immunology of the skin, in: The immunology of host-ectoparasitic arthropod relationship, 1996, pp. 1-29.

[112] Williams C.F., Inoue T., Lucus A.M., Zanotto P.M., Roy P., The complete sequence of four major structural proteins of African horse sickness virus serotype 6: evolutionary relationships within and between the orbiviruses, Virus Res. (1998) 53: 53-73.

[113] Wilson A., Darpel K., Mellor P.S., Where does bluetongue virus sleep in the winter? PLoS Biology (2008) 6:e210.

[114] Wilson A., Mellor P., Bluetongue in Europe: vectors, epidemiology and climate change, Parasitol. Res. (2008) 103:69-77.

[115] Wittmann E.J., Mellor P.S., Baylis M., Effect of temperature on the transmission of orbiviruses by the biting midge, Culicoides sonorensis, Med. Vet. Entomol. (2002) 16:147-156.

[116] Wohlsein P., Pohlenz J., Salt J., Hamblin C., Immunohistochemical demonstration of African horse sickness antigen in tissues of experimentally infected equines, Arch. Virol. (1998) Suppl. 14:57-65.

[117] Xu G., Wilson W., Mecham J., Murphy K., Zhou E.-M., Tabachnick W.J., VP7: an attachment protein of bluetongue virus for cellular receptors in Culicoides variipennis, J. Gen. Virol. (1997) 78:1617-1623. 